\title{
Lymph nodes may be a source for immunetherapy in gastric cancer
}

\author{
Paula Baraúna Assumpção ${ }^{1,2}$, Erika Couto Canelas ${ }^{2}$, Aline Cruz Ramos², Ana \\ Anaissi ${ }^{2,4}$, João Felipe Acioli ${ }^{2,3}$, Geraldo Ishak ${ }^{2,3}$, Sidney Santos ${ }^{1,2}$, Samia Demachki ${ }^{2,4}$ \\ and Paulo Assumpção ${ }^{2}$ \\ 'Laboratório Genética Humana e Médica, Universidade Federal do Pará, Belém-PA, Brasil \\ ${ }^{2}$ Núcleo de Pesquisas em Oncologia, Hospital Universitário João de Barros Barreto, Belém-PA, Brasil \\ ${ }^{3}$ Serviço de Cirurgia do Hospital Universitário João do Barros Barreto, Belém-PA, Brasil \\ ${ }^{4}$ Instituto de Ciências da Saúde, Universidade Federal do Pará, Belém-PA, Brasil \\ Correspondence to: Paulo Assumpção, email: assumpcaopp@gmail.com \\ Keywords: gastric cancer; immunotherapy; lymph nodes \\ Received: January 15, $2020 \quad$ Accepted: April 10, $2020 \quad$ Published: May 12, 2020
}

Copyright: Assumpção et al. This is an open-access article distributed under the terms of the Creative Commons Attribution License 3.0 (CC BY 3.0), which permits unrestricted use, distribution, and reproduction in any medium, provided the original author and source are credited.

\section{ABSTRACT}

Background: adoptive immunotherapy is a promising cancer therapy. Immune cells are capable of recognizing and destroying cancer cells and represent a powerful strategy, however, this approach remains technically complicated, due to the need to select and isolate immune cells from these, present cancer antigens to those cells, expanding and reinjecting them. Lymph nodes recovered during gastric cancer surgery may represent an option for immunotherapy, since they harbor an enormous amount of immune cells, which have already been presented to cancer antigens. The advantage of selecting only cancer- negative lymph has not been determined yet. The status of immune checkpoints in the immune cells within the lymph nodes was analyzed in order to try to solve this problem.

Materials and Methods: Tissue microarrays were constructed and automated immunostaining for PD-1 and PD-L1 was performed on 143 lymph nodes from 70 patients with gastric adenocarcinoma.

Results: In positive nodes, PD-L1 was only positivity in cancer cells (6\%) and PD-1 was positive for B lymphocytes (60\%), T lymphocytes $(70 \%)$ and one case in cancer cells $(2.5 \%)$. In negative nodes, most cases were positive for PD-1 in B (73.1\%) and $\mathrm{T}(71.65 \%)$ lymphocytes.

Conclusions: Expression of PD-1 and PD-L1 in gastric cancer lymph nodes was demonstrated for the first time. PD-1 is expressed in positive and negative nodes, which could activate the PD-1 pathway. Lymphocytes from tumor-free lymph nodes were negative for PD-L1, and this might represent an advantage for selecting these lymph nodes as a potential source of immune cells for adoptive immunotherapy.

\section{INTRODUCTION}

Elements of the immune repertoire have gained increased attention since "avoidance of immune response" as one of the hallmarks of cancer [1] and introduction of immune check point therapy for diverse cancer types [25]. Nevertheless, the importance of preserving effectors of the immune system (such as lymphocytes in regional lymph nodes) that do not harbor cancer cells, seems to be under- valued.
Classical immune treatments, including adoptive therapy [6], have evolved to include the refined ex-vivo manipulation of diverse cells from the immune set, which has allowed innovative approaches both in clinical practice and as part of ongoing experimental and translational innovations [7-11]. The resection of regional lymph nodes in gastric cancer surgery is considered one of the most relevant advances, since it seems to be associated with benefits both in the reduction of local recurrence and probably in terms of survival [12-14]. 
The guidelines for gastric cancer lymphadenectomy $[15,16]$ include the systematic resection of lymph nodes regardless of whether they are positive or negative for cancer [17].

The enlargement of regional lymph nodes occurs due to the clonal expansion of lymphocytes that were exposed to immunogenic tumor cells, and as a consequence, became able to identify these tumor cells and eliminate them. These lymph nodes are probably not enemies that should definitely be discarded, but rather, they may be useful elements that can help control the disease. The large number of immune cells available inside the lymph nodes and the large number of retrieved lymph nodes might represent an optional source of immune cells that can be used for adoptive therapy. Moreover, the possibility for the selection of tumor-free lymph nodes, as will be discussed below, should represent an extra advantage that should be considered in the setting of adoptive immunotherapy.

\section{The use of lymphocytes from negative lymph nodes as ammunition against gastric cancer}

Reflecting on the strategies that use tumor infiltrating lymphocytes (TILs) that are recovered from tumors and expanded in vitro and that are finally reinfused into patients, the aim is that these "adopted" cells might find and destroy tumor cells from where they were collected $[6,18]$. Lymphocytes from lymph nodes could also exert the same functions, and additionally, might have the following advantages over TILs: lymphocytes are plentiful and easily available [19, 20]; if only negative lymph nodes are selected, undesirable effects of the tumor microenvironment would be avoided; lymph nodes are systematically resected during gastric cancer surgeries.

Unfortunately, in the war against gastric cancer, the "enemy" dominates the microenvironment in the great majority of battles. One of the most successful applied strategies in regard to tumor cells is the use of rogue messages to turn off immune system defenses. This is the case with PD-L1 and PD-L2 expression by tumor cells, as their expression activates PD-1 and results in the inhibition of the lymphocyte response; this leaves tumor cells undisturbed [21-25].

By using TILs collected from the tumor microenvironment, the strength of treatment might be partially repressed by the tumor strategy described herein, as should be the case when lymphocytes from positive lymph nodes are used. However, this would not be the case if the lymphocytes were selected from tumor-free lymph nodes, which would avoid the cancer strategy of silencing the immune response.

To determine if negative lymph nodes retrieved by a typical lymphadenectomy procedure performed during conventional surgical treatment for gastric cancer could be a cell source for adoptive immunotherapy, we analyzed the expression of PD-1 and PD-L1 in positive and negative lymph nodes.

\section{RESULTS}

The results are expressed according to the immunostaining for PD-1 and PD-L1 in both immune cells and cancer cells and are reported in lymph nodes retrieved as part of lymphadenectomy during routine gastrectomies for adenocarcinomas.

The most of cases were men over 50 years of age who were treated at advanced disease stages; most cases were of the intestinal type according to the Lauren classification. The results of immunostaining for both PD-1 and PD-L1 among positive lymph nodes are shown according to histopathologic characteristics (Table 1).

PD-L1 was related to well differentiated tumors, of intestinal type, in advanced stages with positive lymph nodes. While PD-1 positive cases included both low and high grade tumors, either in early and advanced stages, mainly from intestinal type and with positive lymph nodes.

PD-L1 positivity in cancer cells was observed in two cases (6\%) (Figure 1B), which were both from advancedstage disease, and were of the intestinal type; no staining was observed in immune cells (Figure 1A). In regard to PD-1, among immune cells, 24 cases had positive B lymphocytes (60\%), while 28 cases had positive T lymphocytes (70\%); staining was negative in all macrophages. Only one case presented PD-1 positivity in cancer cells (2.5\%) (Table 2$)$.

In terms of the negative lymph nodes, the immunostaining for both PD-1 and PD-L1 show the follow distribution according histopathologic characteristics (Table 3).

PD-1 positive cases included both low and high grade tumors, either in early and advanced stages, mainly from intestinal type and with positive lymph nodes. PD-L1 was negative since there weren't cancer cells.

Three cases demonstrated PD-L1 positivity in macrophages, but none demonstrated positivity in lymphocytes, and obviously, none demonstrated positivity in cancer cells (Table 4).

These results are represented in Figure 2. On the contrary, the majority of cases presented PD-1 positivity both in $\mathrm{B}(73.1 \%)$ and $\mathrm{T}(71.65 \%)$ lymphocytes (Figure $2 \mathrm{~A}$ and $2 \mathrm{C}$ ). In addition, two cases presented PD-1 positivity in macrophages (Figure $2 \mathrm{~B}$ and $2 \mathrm{D}$ ).

\section{DISCUSSION}

Adoptive immunotherapy has shown promising results in individuals with different cancer types [26, 27], and in terms of gastric cancer treatment, this therapy has also seemed to improve survival [28]. Nevertheless, due to new concepts in immunotherapy and cancer, the microenvironment has gained relevance and has emerged as a necessary concomitant target to consider while selecting cancer immunotherapy strategies [29, 30].

Cancer cells appear to control the tumor microenvironment, including the avoidance of local 
Table 1: Immunostaining for PD-1 and PD-L1 in positive lymph nodes according to histopathologic characteristics

\begin{tabular}{|c|c|c|c|c|c|c|}
\hline \multirow[t]{2}{*}{ Histopathological Features } & & \multicolumn{2}{|c|}{ PD-L1 } & & \multicolumn{2}{|c|}{ PD-1 } \\
\hline & & Negative & Positive & & Negative & Positive \\
\hline Histologic grade & $n=30(\%)$ & & & $n=40(\%)$ & & \\
\hline G1 (well differentiated) & $19(63,3)$ & $17(56,6)$ & $2(6,7)$ & $28(70)$ & $7(17,5)$ & $21(52,5)$ \\
\hline G2 (Moderately differentiated) & $2(6,7)$ & $2(6,7)$ & 0 & $2(5)$ & $1(2,5)$ & $1(2,5)$ \\
\hline G3 (Poorly differentiated) & $9(30)$ & $9(30)$ & 0 & $10(25)$ & $4(10)$ & $6(15)$ \\
\hline \multicolumn{7}{|l|}{ Histologic type } \\
\hline Intestinal & $19(63,3)$ & $17(56,6)$ & $2(6,7)$ & $28(70)$ & $7(17,5)$ & $21(52,5)$ \\
\hline Diffuse & $9(30)$ & $9(30)$ & 0 & $10(25)$ & $4(10)$ & $6(15)$ \\
\hline Mixed & $2(6,7)$ & $2(6,7)$ & 0 & $2(5)$ & $1(2,5)$ & $1(2,5)$ \\
\hline \multicolumn{7}{|l|}{ pT } \\
\hline T1 (early) & $1(3,3)$ & $1(3,3)$ & 0 & $2(5)$ & 0 & $2(5)$ \\
\hline T2, T3 e T4 (Advanced) & $29(96,7)$ & $27(90)$ & $2(6,7)$ & $37(92,5)$ & $12(30)$ & $25(62,5)$ \\
\hline Not reported & 0 & 0 & 0 & $1(2,5)$ & 0 & $1(2,5)$ \\
\hline \multicolumn{7}{|l|}{ Pn } \\
\hline N1 & $4(13,3)$ & $4(13,3)$ & 0 & $6(15)$ & $1(2,5)$ & $5(12,5)$ \\
\hline$N 2$ & $12(40)$ & $12(40)$ & 0 & $14(35)$ & $3(7,5)$ & $11(27,5)$ \\
\hline$N 3$ & $14(46,7)$ & $12(40)$ & $2(6,7)$ & $20(50)$ & $8(20)$ & $12(30)$ \\
\hline \multicolumn{7}{|l|}{$\mathrm{pM}$} \\
\hline$M x$ & $28(93,3)$ & $26(86,6)$ & $2(6,7)$ & $37(92,5)$ & $10(25)$ & $27(67,5)$ \\
\hline M1 & $2(6,7)$ & $2(6,7)$ & 0 & $3(7,5)$ & $2(5)$ & $1(2,5)$ \\
\hline
\end{tabular}

cells of the immune system [1] via the inhibition of the host response against the disease. Therefore, we realized that the selection and isolation of $\mathrm{T}$ cells and even other immune cells that are able to recognize and eliminate tumor cells, but that are not subjugated by cancer cells with the power to silence the immune response, might represent a potential approach to be investigated in gastric cancer immunotherapy.

Gastrectomy with lymphadenectomy is the standard surgical procedure for the treatment of gastric cancer [15, 16]. The systematic resection of lymph nodes provides a large number of both negative and positive lymph nodes, depending on the stage of the disease. The large number of lymphocytes and/or other immune cells retrieved from the negative lymph nodes constitutes a source of possible "bullets" to be selected, saved, and improved, with the aim to allow efficient and targeted adoptive immunotherapy.

The presence of cancer cells in the lymph nodes, which are considered classical "positive nodes," implies the possibility of an ongoing cancer cell strategy in which cancer cells escape the immune response. This was previously demonstrated by the activation of immune check points as a consequence of tumor cell expression of PD-L1 and other molecules in the tumor microenvironment.
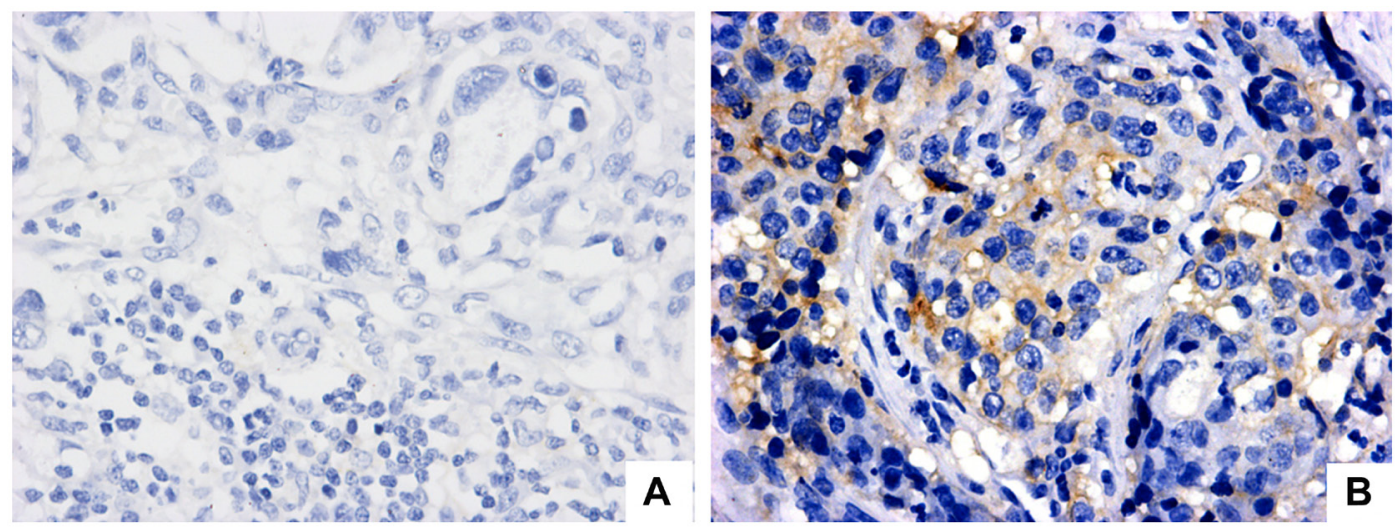

Figure 1: PD-L1 expression evaluation in regional lymph node with metastatic gastric adenocarcinoma (positive lymph node). (A) Negative staining in neoplastic cells (magnification 40×). (B) PD-L1 positive cytoplasmatic staining in neoplastic cells (magnification 40×). 
Table 2: Immunostaining for PD-1 and PD-L1 in B lymphocytes, T lymphocytes, macrophages and neoplastic cells from positive lymph nodes

\begin{tabular}{lcc}
\hline Cell Type & PD-L1 & PD-1 \\
\cline { 2 - 3 } & $\boldsymbol{n}=\mathbf{3 0}(\mathbf{\%})$ & $\boldsymbol{n}=\mathbf{4 0}(\mathbf{\%})$ \\
\hline B Lymphocytes & & \\
NEGATIVE $(<1 \%)$ & $30(100)$ & $16(40)$ \\
$>1-5 \%$ & 0 & 0 \\
$>5-10 \%$ & 0 & $15(37,5)$ \\
$>10-25 \%$ & 0 & $9(22,5)$ \\
T lymphocytes & & $12(30)$ \\
NEGATIVE $<1 \%$ & $30(100)$ & $28(70)$ \\
POSITIVE $>1-5 \%$ & 0 & $40(100)$ \\
Macrophages & & 0 \\
NEGATIVE $<1 \%$ & $30(100)$ & \\
POSITIVE $>1-5 \%$ & 0 & $39(97,5)$ \\
Neoplastic cells & & $1(2,5)$ \\
NEGATIVE $<1 \%$ & $28(94)$ & $2(6)$ \\
POSITIVE $>1-5 \%$ & & \\
\hline
\end{tabular}

Table 3: Immunostaining for PD-1 and PD-L1 in negative lymph nodes according to histopathologic characteristics

\begin{tabular}{|c|c|c|c|c|c|c|}
\hline \multirow[t]{2}{*}{ Histopathological Features } & & \multicolumn{2}{|c|}{ PD-L1 } & & \multicolumn{2}{|c|}{ PD-1 } \\
\hline & & Negative & Positive & & Negative & Positive \\
\hline Histologic grade & $n=68(\%)$ & & & $n=67(\%)$ & & \\
\hline G1 (well differentiated) & $48(70,6)$ & $48(70,6)$ & 0 & $48(61,6)$ & $13(19,4)$ & $35(52,2$ \\
\hline G2 (Moderately differentiated) & $2(2,94)$ & $2(2,94)$ & 0 & $2(3)$ & 0 & $2(3)$ \\
\hline G3 (Poorly differentiated) & $18(26,5)$ & $18(26,5)$ & 0 & $17(25,4)$ & $3(4,5)$ & $14(20,9)$ \\
\hline \multicolumn{7}{|l|}{ Histological type } \\
\hline Intestinal & $48(70,6)$ & $48(70,6)$ & 0 & $48(61,6)$ & $13(19,4)$ & $35(52,2)$ \\
\hline Diffuse & $18(26,5)$ & $18(26,5)$ & 0 & $17(25,4)$ & $3(4,5)$ & $14(20,9)$ \\
\hline Mixed & $2(2,94)$ & $2(2,94)$ & 0 & $2(3)$ & 0 & $2(3)$ \\
\hline \multicolumn{7}{|l|}{ pT } \\
\hline T1 (early) & $10(14,7)$ & $10(14,7)$ & 0 & $10(14,9)$ & $2(3)$ & $8(11,9)$ \\
\hline T2, T3 e T4 (Advanced) & $53(77,9)$ & $53(77,9)$ & 0 & $53(79,1)$ & $12(17,9)$ & $41(61,2)$ \\
\hline Not reported & $5(7,35)$ & $5(7,35)$ & 0 & $4(6)$ & $2(3)$ & $2(3)$ \\
\hline \multicolumn{7}{|l|}{$\mathrm{pN}$} \\
\hline NO & $14(20,6)$ & $14(20,6)$ & 0 & $14(20,9)$ & $4(6)$ & $10(14,9)$ \\
\hline N1 & $13(19,1)$ & $13(19,1)$ & 0 & $13(19,4)$ & $2(3)$ & $11(16,4)$ \\
\hline$N 2$ & $16(23,5)$ & $16(23,5)$ & 0 & $16(23,9)$ & $3(4,5)$ & $13(19,4)$ \\
\hline$N 3$ & $20(29,4)$ & $20(29,4)$ & 0 & $21(31,3)$ & $6(8,9)$ & $15(22,4)$ \\
\hline N4 & $1(1,5)$ & $1(1,5)$ & 0 & 0 & 0 & 0 \\
\hline Not reported & $4(5,9)$ & $4(5,9)$ & 0 & $3(4,5)$ & $1(1,5)$ & $2(3)$ \\
\hline \multicolumn{7}{|l|}{$\mathrm{pM}$} \\
\hline$M x$ & $66(97)$ & $66(97)$ & 0 & $64(95,5)$ & $15(22,4)$ & $49(73,1)$ \\
\hline M1 & $2(3)$ & $2(3)$ & 0 & $3(4,5)$ & $1(1,5)$ & $2(3)$ \\
\hline
\end{tabular}


Table 4: Immunostaining for PD-1 and PD-L1 in B lymphocytes, T lymphocytes, and macrophages from negative lymph nodes

\begin{tabular}{lcc}
\hline Cell Type & PD-L1 & PD-1 \\
\hline B Lymphocytes & $\boldsymbol{n}=\mathbf{6 8}(\%)$ & $\boldsymbol{n}=\mathbf{6 7}(\%)$ \\
NEGATIVE $(<1 \%)$ & & \\
$>1-5 \%$ & $68(100)$ & $18(26,9)$ \\
$>5-10 \%$ & 0 & $27(40,3)$ \\
$>10-25 \%$ & 0 & $19(28,35)$ \\
T lymphocytes & 0 & $3(4,5)$ \\
NEGATIVE $<1 \%$ & & $19(28,35)$ \\
POSITIVE $>1-5 \%$ & $68(100)$ & $48(71,65)$ \\
Macrophages & 0 & $65(97)$ \\
NEGATIVE $<1 \%$ & & $2(3)$ \\
POSITIVE $>1-5 \%$ & $65(95,6)$ & $3(4,4)$ \\
\hline
\end{tabular}

The results presented in this preliminary investigation are original since the only published data regarding PD-1 and PD-L1 expression in gastric cancer are related to either tumors [31] or non-cancer gastric mucosae [32]. The results from the current study also corroborate the hypothesis that negative lymph nodes seem to be free of the inhibition of the immune response, which is frequently found in the presence of malignant cells.
Although PD-1 expression was observed in the majority of both positive and negative lymph nodes, the activation of the PD-1 pathway depends on the concomitant expression of its ligand [24]. Since PD-L1 was not expressed in lymphocytes from negative nodes, even in those that expressed PD-1, the inhibition of the immune response by a PD1/PDL1 interaction would never occur, if these lymph nodes were the only ones selected for adoptive immunotherapy. In contrast, the expression
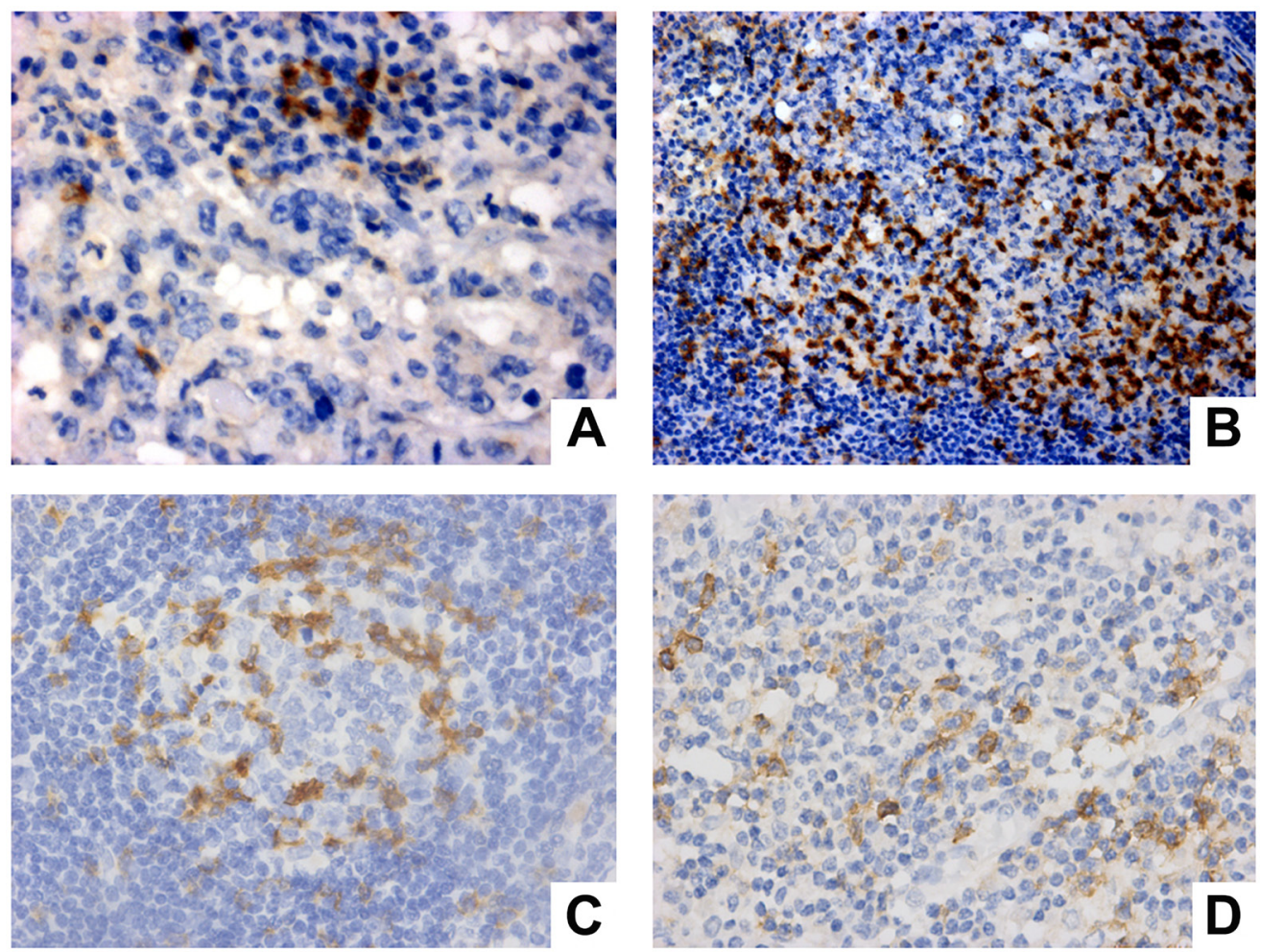

Figure 2: PD-1 expression evaluation in immune cells from positive lymph node (A, B) and negative lymph node (C, D). (A) PD-1 expression in $\mathrm{T}$ lymphocytes (Magnification 40×). (B) expression in centrofollicular B lymphocytes (Magnification 20×). (C) PD-1 expression in centrofollicular B lymphocytes of negative lymph node (Magnification 40×). (D) PD-1 expression in macrophage and T lymphocytes (magnification $40 \times$ ). 
of PD-L1 in "positive nodes" might inhibit the immune response by activation of the PD-1 pathway.

This strengthens the hypothesis of a possible negative influence of using lymphocytes exposed to tumor cells such as TILs or even lymphocytes from positive nodes. Obviously, after the administration of immune cells that have been expanded in vitro, the expression of PD-1 ligands and/or activation of other tumor mechanisms for avoiding the host immune system might protect some cancer cells from immune system attack and subsequent destruction.

As is the case in most wars, the enemies try to eliminate each other and protect themselves while in inconvenient environments. Nevertheless, the criteria for the selection of combatants to send to the battlefield favors the strongest and not ones who are easily subdued by the enemy, even though some might fail at their responsibilities.

The silencing of adoptive immune cells after infusion might occur independently of using cells derived from tumors or lymph nodes and might be circumvented by the concomitant use of immune check point antibodies, if required.

Additionally, PD-1 expression in selected lymphocytes could be definitively silenced in vitro by recently available techniques such as DNA editing [33], like CRISPR [34], which would thus avoid the activation of the PD-1 pathway after re-infusion of the lymphocytes, even in cases of tumors that express PD-1 ligands.

Nevertheless, it seems to make sense to select immune cells that are easily available from routinely retrieved lymph nodes and ones that are not exposed to silencing cues (PD-1 ligands and others), rather than collecting them from the tumor mass.

The small number of PD-L1-positive cells in this casuistry is in accordance with the expected positive expression of this binding protein in primary gastric cancers, since it seems to be related to the EBV molecular subtype, which is the least common among the gastric cancer subtypes [35].

The finding of PD-L1 expression in macrophages was previously reported [36] and might be related to the immune function of these cells, which phagocyte cancer cells and other cell types, and whose aim is to clear the microenvironment of harmful molecules that threaten tissue homeostasis.

Although modest, these preliminary results could be extrapolated to investigations of many other tumors, such as colon cancer, breast cancer and ovarian cancer, for which lymphadenectomy is also applied.

In conclusion, the expression of PD-1 and PDL1 in lymph nodes retrieved during gastrectomies was demonstrated here for the first time. These proteins are expressed in lymphocytes from lymph nodes, but PD-L1 is not expressed in lymphocytes from negative lymph nodes. Negative for malignancy lymph nodes retrieved during gastrectomies might be considered a potential source for gastric cancer immunotherapy.

\section{MATERIALS AND METHODS}

This study was approved by the Universidade Federal do Pará Ethics Committee with CAAE N ${ }^{\circ}$ 43961215.9.0000.5634, all research was performed in accordance with relevant guidelines/regulations and all participants read and signed the written informed consent. One hundred and forty-three lymph nodes from 70 gastric adenocarcinoma patients who submitted to curative intended gastrectomy with D2 classical lymphadenectomies were selected for the analysis. The surgical specimens were evaluated by the same pathologist, and tumors were classified according to the Lauren and WHO standards, and according to the 8th edition of the UICC staging system.

Lymph nodes were initially assessed by conventional microscopy and were classified as positive (with metastasis) or negative (without metastasis). A total of 69 positive lymph nodes and 74 negative lymph nodes were initially stained and were analyzed by microscopy, after which, at least two, representative samples were selected from each node.

\section{Tissue microarrays (TMAs)}

Histological sections from each tissue block were stained with Hematoxylin and Eosin (H\&E) and were carefully reviewed by a pathologist. The most representative areas of each lymph node were selected for analysis. Cylindrical cores from the selected areas were removed to construct TMA blocks using TMA Grand Master (3DHISTECH Ltd.) according to the manufacturer's instructions.

\section{Immunohistochemistry}

The immunohistochemistry procedures were performed at Gx Ventana ${ }^{\circledR}$ (Ventana Medical Systems, Inc. Tucson, AZ, USA) with an Ultra View Universal Dab Detection Kit. Briefly, 3- $\mu \mathrm{m}$ - thick sections were obtained from the TMA blocks, and immunohistochemistry was performed using a rabbit polyclonal PDL-1 antibody $\left(\right.$ Abcam $^{\circledR}$, ab205921, 28-8, RabMab) at a 1:200 dilution and a mouse monoclonal PD-1 antibody (Abcam ${ }^{\circledR}$, ab52587, NAT-105) at a 1:50 dilution. Both tumour cells and immune cells, such as B and T lymphocytes and macrophages, were analyzed. The criteria for positive PD-L1 protein staining in tumor cells was restricted to cytoplasmic membrane staining, either partially or completely, while for immune cells, membrane or cytoplasmic staining for both PD-L1and PD-1 was considered positive [37].

In some cases, although the TMAs contained two samples from each case, due to technical problems, the analyses failed for one or both antibodies. These failures primarily include disruption of the samples, following 
performing the transfer of the slices from the receptor blocks during construction of the TMA slides for staining with the selected antibodies.

\section{Author contributions}

Paula Baraúna Assumpção, Erika Couto Canelas, Aline Cruz Ramos and Paulo Assumpção made the design of the work and wrote the main manuscript text. Paulo Assumpção, Geraldo Ishak and João Felipe Acioli, applied written informed consent to all the participants and collected the biological material. Samia Demachki and Ana Anaissi did the histopathologic analysis, the tissue microarray and the immunohistochemistry. Sidney Santos did the analysis and interpretation of data. Paulo Assumpção, Samia Demachki and Sidney Santos supervised the work of all. All authors reviewed the manuscript.

\section{CONFLICTS OF INTEREST}

All authors declare no competing statements.

\section{REFERENCES}

1. Hanahan D, Weinberg RA. Hallmarks of cancer: the next generation. Cell. 2011; 144:646-674. https://doi. org/10.1016/j.cell.2011.02.013. [PubMed]

2. Pardoll DM. The blockade of immune checkpoints in cancer immunotherapy. Nat Rev Cancer. 2012; 12:252-264. https:// doi.org/10.1038/nrc3239. [PubMed]

3. Alme AK, Karir BS, Faltas BM, Drake CG. Blocking immune checkpoints in prostate, kidney, and urothelial cancer: an overview. Urol Oncol. 2016; 34:171-81. https:// doi.org/10.1016/j.urolonc.2016.01.006. [PubMed]

4. Bidnur S, Savdie R, Black PC. Inhibiting Immune Checkpoints for the Treatment of Bladder Cancer. Bladder Cancer. 2016; 2:15-25. https://doi.org/10.3233/BLC-150026. [PubMed]

5. Swart M, Verbrugge I, Beltman JB. Combination Approaches with Immune-Checkpoint Blockade in Cancer Therapy. Front Oncol. 2016; 6:233. https://doi.org/10.3389/ fonc.2016.00233. [PubMed]

6. Rosenberg SA, Packard BS, Aebersold PM, Solomon D, Topalian SL, Toy ST, Simon P, Lotze MT, Yang JC, Seipp CA, Simpson C, Carter C, Bock S, et al. Use of tumor-infiltrating lymphocytes and interleukin-2 in the immunotherapy of patients with metastatic melanoma. A preliminary report. N Engl J Med. 1988; 319:1676-1680. https://doi.org/10.1056/NEJM198812223192527. [PubMed]

7. Carlsten M, Childs RW. Genetic Manipulation of NK Cells for Cancer Immunotherapy: Techniques and Clinical Implications. Front Immunol. 2015; 6:266. https://doi. org/10.3389/fimmu.2015.00266. [PubMed]
8. Radice E, Bellone G, Miranda V. Enhancement of the Immunostimulatory Functions of Ex Vivo-Generated Dendritic Cells from Early-Stage Colon Cancer Patients by Consecutive Exposure to Low Doses of SequentialKinetic-Activated IL-4 and IL-12. A Preliminary Study. Transl Oncol. 2015; 8:327-338. https://doi.org/10.1016/j. tranon.2015.06.005. [PubMed]

9. Sharpe M, Mount N. Genetically modified T cells in cancer therapy: opportunities and challenges. Dis Model Mech. 2015; 8:337-350. https://doi.org/10.1242/dmm.018036. [PubMed]

10. Digiusto DL, Kiem HP. Current translational and clinical practices in hematopoietic cell and gene therapy. Cytotherapy. 2012; 14:775-790. https://doi.org/10.3109/14 653249.2012.694420. [PubMed]

11. Visioni A, Skitzki J. Technical Considerations for the Generation of Adoptively Transferred T Cells in Cancer Immunotherapy. Cancers. 2016; 8:86. https://doi.org/10.3390/ cancers8090086. [PubMed]

12. Adachi Y, Oshiro T, Okuyama T, Kamakura T, Mori M, Maehara Y, Sugimachi K. A simple classification of lymph node level in gastric carcinoma. Am J Surg. 1995; 169:382-5. https://doi.org/10.1016/S0002-9610(99)80181-0. [PubMed]

13. Karpeh MS, Leon L, Klimstra D, Brennan MF. Lymph Node Staging in Gastric Cancer: Is Location More Important Than Number?: An Analysis of 1,038 Patients. Ann Surg. 2000; 232:362-371. https://doi.org/10.1097/00000658200009000-00008. [PubMed]

14. Schmidt B, Yoon SS. D1 Versus D2 Lymphadenectomy for Gastric Cancer. J Surg Oncol. 2013; 107:259-264. https:// doi.org/10.1002/jso.23127. [PubMed]

15. Japanese Gastric Cancer Association. Japanese classification of gastric carcinoma: 3rd English edition. Gastric Cancer. 2011; 14:101-112. https://doi.org/10.1007/s10120-0110041-5. [PubMed]

16. Japanese Gastric Cancer Association. Japanese gastric cancer treatment guidelines 2014 (ver. 4). Gastric Cancer. 2017; 20:119. https://doi.org/10.1007/s10120-016-0622-4. [PubMed]

17. Rosa F, Costamagna G, Doglietto GB, Alfieri S. Classification of nodal stations in gastric cancer. Transl Gastroenterol Hepatol. 2017; 2:2. https://doi.org/10.21037/ tgh.2016.12.03. [PubMed]

18. Rosenberg SA, Yang JC, Sherry RM, Kammula US, Hughes MS, Phan GQ, Citrin DE, Restifo NP, Robbins PF, Wunderlich JR, Morton KE, Laurencot CM, Steinberg SM, et al. Durable complete responses in heavily pretreated patients with metastatic melanoma using T-cell transfer immunotherapy. Clin Cancer Res. 2011; 17:4550-57. https:// doi.org/10.1158/1078-0432.CCR-11-0116. [PubMed]

19. Wang LX, Huang WX, Graor H, Cohen PA, Kim JA, Shu S, Plautz GE. Adoptive immunotherapy of cancer with polyclonal, 108-fold hyperexpanded, CD4+ and CD8+ T cells. J Transl Med. 2004; 2:41. https://doi. org/10.1186/1479-5876-2-41. [PubMed] 
20. Visioni A, Zhang M, Graor H, Kim J. Expansion of melanoma-specific $\mathrm{T}$ cells from lymph nodes of patients in stage III: implications for adoptive immunotherapy in treating cancer. Surgery. 2012; 152:557-65. https://doi. org/10.1016/j.surg.2012.07.002. [PubMed]

21. Saito H, Kuroda H, Matsunaga T, Osaki T, Ikeguchi M. Increased PD-1 Expression on CD4p and CD8p T Cells Is Involved in Immune Evasion in Gastric Cancer. J Surg Oncol. 2013; 107:517-522. https://doi.org/10.1002/ jso.23281. [PubMed]

22. Sabatier R, Finetti P, Mamessier E, Adelaide J, Chaffanet M, Ali HR, Viens P, Caldas C, Birnbaum D, Bertucci F. Prognostic and predictive value of PDL1 expression in breast cancer. Oncotarget. 2015; 6:5449-64. https://doi.org/ 10.18632/oncotarget.3216. [PubMed]

23. Gros A, Robbins PF, Yao X, Li YF, Turcotte S, Tran E, Wunderlich JR, Mixon A, Farid S, Dudley ME, Hanada K, Almeida JR, Darko S, et al. PD-1 identifies the patientspecific CD8+tumor-reactive repertoire infiltrating human tumors. J Clin Invest. 2014; 124:2246-2259. https://doi. org/10.1172/JCI73639. [ PubMed]

24. de Guillebon E, Roussille P, Frouin E, Tougeron D. Anti program death-1/anti program death- ligand 1 in digestive cancers. World J Gastrointest Oncol. 2015; 7:95-101. https://doi.org/10.4251/wjgo.v7.i8.95. [PubMed]

25. Bardhan K, Anagnostou T, Boussiotis VA. The PD1:PD-L1/2 Pathway from Discovery to Clinical Implementation. Front Immunol. 2016; 7:550. https://doi. org/10.3389/fimmu.2016.00550. [PubMed]

26. Besser MJ, Shapira-Frommer R, Treves AJ, Zippel D, Itzhaki O, Hershkovitz L, Levy D, Kubi A, Hovav E, Chermoshniuk N, Shalmon B, Hardan I, Catane R, et al. Clinical responses in a phase II study using adoptive transfer of short-term cultured tumor infiltration lymphocytes in metastatic melanoma patients. Clin Cancer Res. 2010; 16:2646-2655. https://doi.org/10.1158/1078-0432.CCR10-0041. [PubMed]

27. Zhang G, Zhao H, Wu J, Li J, Xiang Y, Wang G, Wu L, Jiao $\mathrm{S}$. Adoptive immunotherapy for non- small cell lung cancer by NK and cytotoxic T lymphocytes mixed effector cells: retrospective clinical observation. Int Immunopharmacol. 2014; 21:396-405. https://doi.org/10.1016/j.intimp.2014.04.026. [PubMed]

28. Kono K, Takahashi A, Ichihara F, Amemiya H, Iizuka H, Fujii H, Sekikawa T, Matsumoto Y. Prognostic Significance of Adoptive Immunotherapy with Tumorassociated Lymphocytes in Patients with Advanced Gastric Cancer: A Randomized Trial. Clin Cancer Res. 2002; 8:1767-71. [PubMed]
29. Mellman I, Coukos G, Dranoff G. Cancer immunotherapy comes of age. Nature. 2011; 480:480-489. https://doi. org/10.1038/nature10673. [PubMed]

30. Sunay ME, Marincola F, Khleif SN, Silverstein SC, Fox BA, Galon J, Emens L. Focus on the target: the tumor microenvironment, Society for Immunotherapy of Cancer Annual Meeting Workshop, October 24th25th 2012. J Immunother Cancer. 2013; 1:9. https://doi. org/10.1186/2051-1426-1-9.

31. Lee SM, Chow LQ. A new addition to the PD-1 checkpoint inhibitors for non-small cell lung cancer-the antiPDL1 antibody-MEDI4736. Transl Lung Cancer Res. 2014; 3:408-410. https://doi.org/10.3978/j.issn.22186751.2014.11.10. [PubMed]

32. Das S, Suarez G, Beswick EJ, Sierra JC, Graham DY, Reyes VE. Expression of B7-H1 on gastric epithelial cells: its potential role in regulating $\mathrm{T}$ cells during Helicobacter pylori infection. J Immunol. 2006; 176:3000-3009. https:// doi.org/10.4049/jimmunol.176.5.3000. [PubMed]

33. Calos MP. Genome Editing Techniques and Their Therapeutic Applications. Clin Pharmacol Ther. 2017; 101:42-51. https://doi.org/10.1002/cpt.542. [PubMed]

34. Chira S, Gulei D, Hajitou A, Zimta AA, Cordelier P, Berindan-Neagoe I. CRISPR/Cas9: transcending the reality of genome Editing. Mol Ther Nucleic Acids. 2017; 7:211222. https://doi.org/10.1016/j.omtn.2017.04.001. [PubMed]

35. Cancer Genome Atlas Research Network. Comprehensive molecular characterization of gastric adenocarcinoma. Nature. 2014; 513:202-209. https://doi.org/10.1038/ nature13480. [PubMed]

36. Schalper KA, Carvajal-Hausdorf D, McLaughlin J, Velcheti V, Chen L, Sanmamed M, Herbst RS, Rimm DL. Clinical significance of PD-L1 protein expression on tumorassociated macrophages in lung cancer. J Immunother Cancer. 2015; 3:P415. https://doi.org/10.1186/2051-14263-S2-P415.

37. Scheel AH, Dietel M, Heukamp LC, Jöhrens K, Kirchner T, Reu S, Rüschoff J, Schildhaus U, Schirmacher P, Tiemann M, Warth A, Weichert W, Fischer RN, et al. Harmonized PD-L1 immunohistochemistry for pulmonary squamouscell and adenocarcinoma. Mod Pathol. 2016; 29:1165-1172. https://doi.org/10.1038/modpathol.2016.117. [PubMed] 